\title{
Physical and mechanical properties of $\mathrm{Ti}_{1-x} \mathrm{Si}_{x} \mathrm{~N}$ films
}

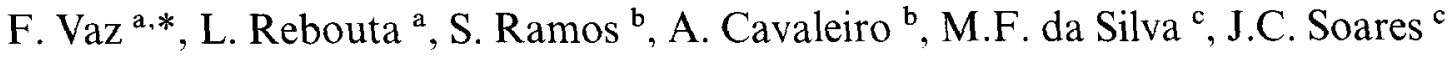 \\ a Departamento Fisica. Universidade do Minho, Azurém, 4800 Guimarães, Portugal

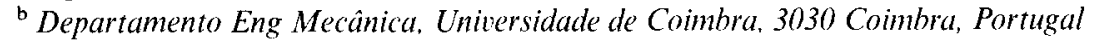 \\ ' ITN. Departamento de Física, E.N.10,2685 Sacavém, Portugal
}

\begin{abstract}
$\mathrm{Ti}_{1-x} \mathrm{Si}_{x} \mathrm{~N}$ coatings with $0<x<0.30$ and thicknesses ranging from 1.2 to $3.3 \mu \mathrm{m}$, were deposited on to polished high-speed steel substrates by r.f. reactive magnetron sputtering. The atomic composition of the samples was measured by Rutherford backscatering spectrometry (RBS), and the texture was determined by X-ray diffraction (XRD). Great improvements in hardness and adhesion behaviour were obtained when compared to TiN. Hardness results and adhesion behaviour as a function of the Si content will be shown and discussed. The $\mathrm{Ti}_{0.85} \mathrm{Si}_{0.15} \mathrm{~N}$ sample presented the best results with a hardness value of about $36 \mathrm{GPa}$ and a critical load for total failure around 70 N. 1998 Elsevier Science S.A.
\end{abstract}

Keywords: Rutherford back-scattering spectrometry; Silicon; Titanium; X-ray diffraction

\section{Introduction}

Hard wear-resistant coatings are increasingly being used in tooling applications to improve the properties and functionality of several engineering materials. However, despite their undoubted success, the physical and specially mechanical properties of these thin hard coatings are often poorly characterised and hardly understood. When considering the performance and durability of a coating/substrate system, the hardness and adhesion of the coating to the substrate should always be two of the first requirements that one should consider. Microhardness testing and scratch adhesion testing are two of the most commonly used techniques for the characterisation of mechanical properties. Although these tests provide different types of information, resistance to deformation and coating adhesion respectively, these two techniques are closely related. In both tests, an indenter is brought into contact with the sample, causing irreversible deformation of the coating/substrate system. In this study, the results describing the behaviour of $\mathrm{Ti}_{1-x} \mathrm{Si}_{x} \mathrm{~N}$ films submitted to scratch and hardness tests are presented, and the effects of the variation of the Si content on the properties of the coating are discussed in some detail.

\footnotetext{
* Corresponding author. Fax: + 35153510153 ;

e-mail: fvaz@fisica.vminho.pt
}

\section{Experimental}

Polished high-speed steel (AISI M2) and silica glass substrates were coated with $(\mathrm{Ti}, \mathrm{Si}) \mathrm{N}$ by reactive r.f. magnetron sputtering from high-purity $\mathrm{Ti}$ and $\mathrm{Si}$ targets. Depositions were carried out in an $\mathrm{Ar} / \mathrm{N}_{2}$ atmosphere in an Alcatel SCM650 system. All substrates were sputter-etched for $15 \mathrm{~min}$ in a pure $\mathrm{Ar}$ atmosphere with an r.f. power of $200 \mathrm{~W}$. The target-to-substrate distance was kept at $60 \mathrm{~mm}$ in all runs, and the substrate holder rotated over the targets at a constant frequency of $4 \pi / 15 \mathrm{rad} \mathrm{s}^{-1}$, including the TiN sample. The base pressure in the deposition chamber was about $10^{-4} \mathrm{~Pa}$ and rose to about $4 \times 10^{-1} \mathrm{~Pa}$ during depositions. The substrates were heated to 300 and $400^{\circ} \mathrm{C}$, and a negative d.c. bias of $-50 \mathrm{~V}$ was applied. The experiments were carried out with the titanium and silicon targets coupled to r.f. sources $(13.56 \mathrm{MHz})$, with powers in the range of $1.9-3.2 \times 10^{4} \mathrm{~W} \mathrm{~m}^{-2}$ for $\mathrm{Ti}$ and $1.8-2.3 \times 10^{4}$ $\mathrm{W} \mathrm{m}^{-2}$ for Si. The scratch tests were performed in a computer-controlled Sebastian five-A (Quad group) scratch tester fitted with an acoustic detector. The tests were conducted under fixed conditions: a $200-\mu \mathrm{m}$ diamond tip, a constant scratching speed $1 \times 10^{-4} \mathrm{~m} \mathrm{~s}^{-1}$ and a loading rate of $1.2 \mathrm{~N} \mathrm{~s}^{-1}$. Five tests were performed on each sample. The hardness tests were performed in a computer-controlled Fischerscope H100 ultramicrohardness tester, equipped with a Vickers dia- 
mond indenter. The system resolution is better than $1 \mu \mathrm{N}$, and the range of the nominal test load is between $4 \mathrm{mN}$ and $1 \mathrm{~N}$. At the beginning of the test, the indenter approaches the sample at a rate of $1 \mu \mathrm{m} \mathrm{s}^{\mathrm{t}}$. The indentation depths were obtained with a capacitance displacement gage accuracy of $2 \mathrm{~nm}$. On average, six tests were performed on each sample. The atomic composition of the as-deposited samples was measured by RBS. Scanning electron microscopy (SEM) examination was conducted on fractured cross-sections in order to determine the thickness of the films. X-ray diffraction (XRD) experiments were performed in a Philips PW 1710 apparatus using $\mathrm{CuK}_{\alpha}$ radiation.

\section{Results and discussion}

\subsection{Characterisation of the as-deposited samples}

Table 1 presents the thickness (SEM) and atomic composition (RBS) of the samples. Regarding the texture of the as-deposited samples, Fig. 1 shows the X-ray diffraction patterns obtained from the as-deposited $\mathrm{Ti}_{1-x} \mathrm{Si}_{x} \mathrm{~N}$ films. The diffraction lines show a strong (220) texture for an intermediate Si content, a (200) texture for the highest Si content and a strong (111) texture for the lowest Si content. These structures are indexed with the cubic structure, typical of TiN.

\subsection{Adhesion tests}

The scratch adhesion test is actually one of the most generally accepted methods of assessing adhesion behaviour of a particular material, namely films. The minimum load at which a failure occurs is called the first critical load $L_{\mathrm{C} 1}$. The load at which more than $50 \%$ of the coating is removed from the substrate is called the second critical load $L_{\mathrm{C} 2}$. Whereas in the detection of $L_{\mathrm{C} 1}$. optical observation is the most reliable method, the detection of $L_{\mathrm{C} 2}$ can be achieved by three different methods, (1) optical observation, (2) analysis of the

Table 1

Thickness and composition of the samples (the error in the $\mathrm{N}$ atomic composition is about 3 at.\%)

\begin{tabular}{lllll}
\hline Coating & Ti (at.\%) & $\mathrm{Si}($ at.\%) & $\mathrm{N}$ (at.\%) & Thickness $(\mu \mathrm{m})$ \\
\hline $\mathrm{TiN}$ & 50 & - & 50 & 3.3 \\
$\mathrm{Ti}_{0.95} \mathrm{Si}_{0.05} \mathrm{~N}$ & 47.5 & 2.5 & 50 & 1.2 \\
$\mathrm{Ti}_{0.88} \mathrm{Si}_{0.12} \mathrm{~N}$ & 44.0 & 6.0 & 50 & 3.3 \\
$\mathrm{Ti}_{0.85} \mathrm{Si}_{0.15} \mathrm{~N}$ & 42.5 & 7.5 & 50 & 2.2 \\
$\mathrm{Ti}_{0.85} \mathrm{Si}_{0.15} \mathrm{~N}^{\mathrm{a}}$ & 42.5 & 7.5 & 50 & 2.9 \\
$\mathrm{Ti}_{0.70} \mathrm{Si}_{0.30} \mathrm{~N}$ & 35.0 & 15.0 & 50 & 2.2 \\
\hline
\end{tabular}

All samples, except $\mathrm{Ti}_{0.70} \mathrm{Si}_{0.30} \mathrm{~N}$, were produced with a 350 -nm-thick $\mathrm{Ti}$ adhesion layer.

aSubstrate temperature $400^{\circ} \mathrm{C}$.

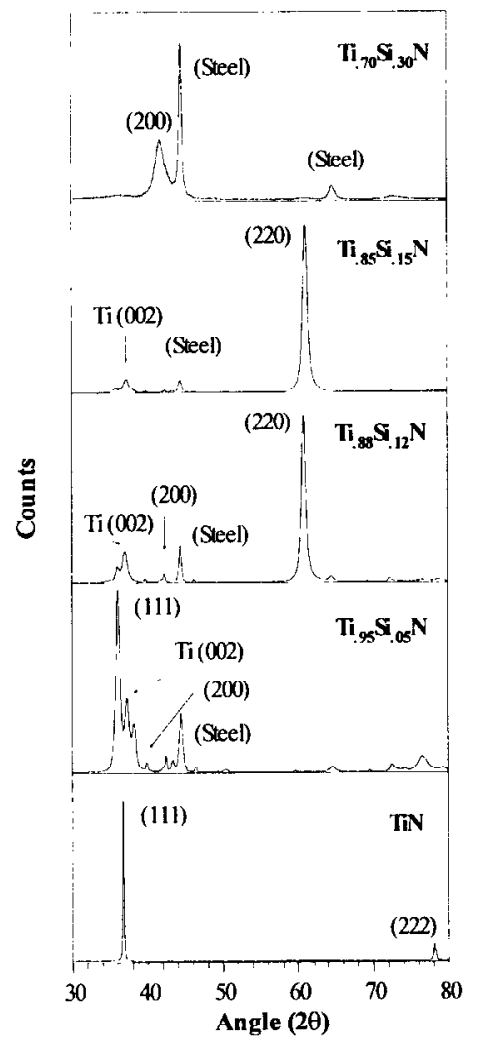

Fig. 1. X-ray diffraction patterns of $\mathrm{Ti}_{1-x} \mathrm{Si}_{x} \mathrm{~N}$ films with $0 \leq x \leq 0.30$.

acoustic emission, and ( 3 ) analysis of the frictional force curve, where total failure is obtained at the inflection point of the increasing frictional force curve [1]. This point corresponds to a maximum in the derivative $d$ (frictional force) $/ d$ (load), and can be obtained by first simulating the frictional force curve and then calculating the derivative of the resulting function. In the detection of $L_{\mathrm{C} 2}$, the three methods were used together in order to minimise the error. These failures are commonly divided into five categories [2]: (1) spalling, (2) buckling, (3) chipping, (4) conformal cracking and (5) tensile cracking.

\subsubsection{Failure modes for $T i_{1-\mathrm{x}} S i_{\mathrm{x}} N$ films}

Fig. 2 shows typical scratch results for the different samples in study. All micrographs were taken from the points of the scratching track where the coating failed.

In the films with the lowest Si content $(x=0.05)$, and for intermediate loads, cracks start to develop and propagate from the edge of the track to the whole surface of the coating. For the regions with total failure, traces of buckling failure and lateral cracking are observed. This behaviour is illustrated in Fig. 2a. For films with an intermediate Si content $(x=0.12$ and $x=$ 0.15 ), buckling failure is the main failure mechanism, which increases with the applied load and is also followed by increasing lateral cracking. Only very small traces of spalling are observed, but some chipping failure 


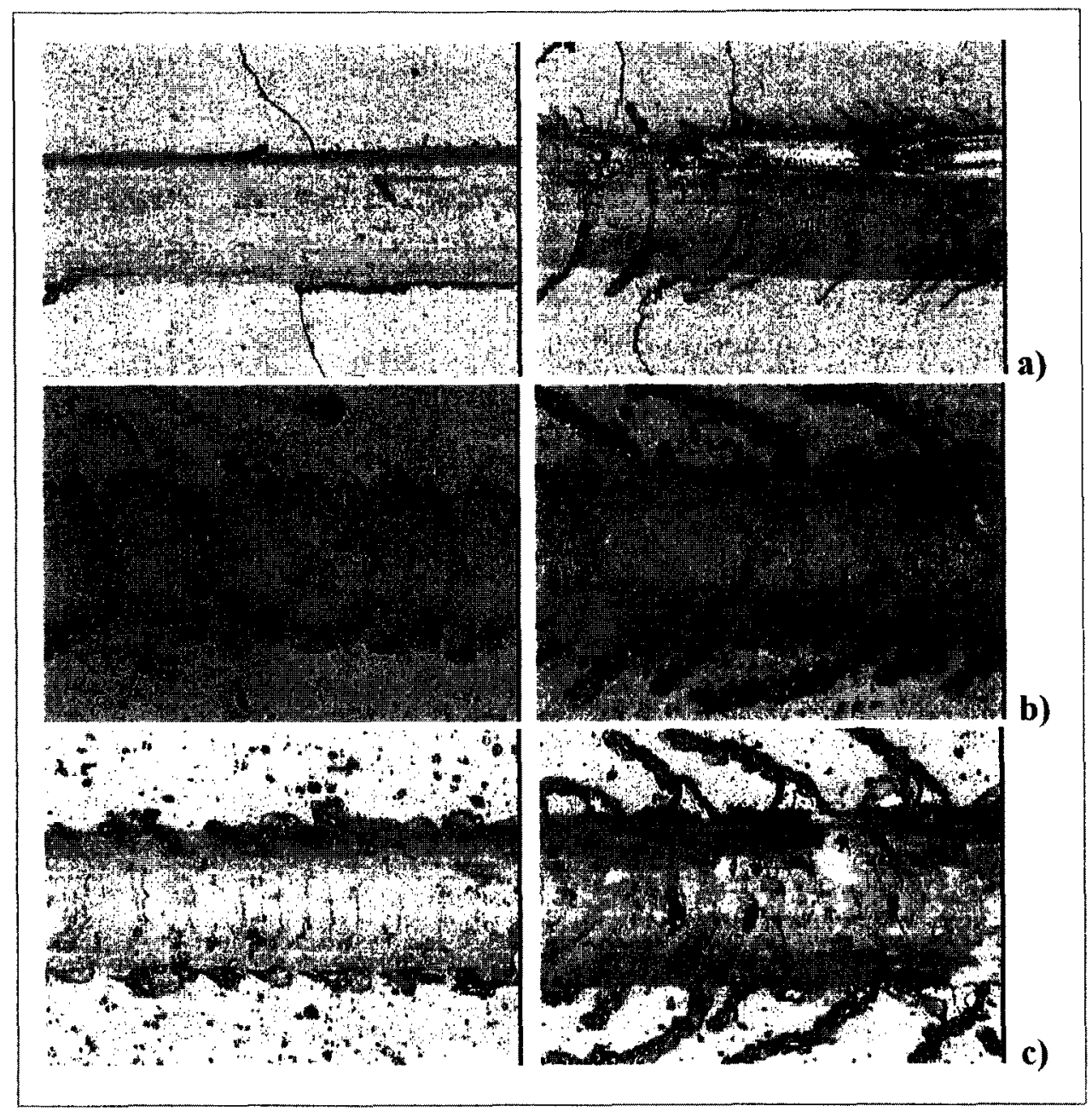

Fig. 2. Failure examples: (a) $\mathrm{Ti}_{0.95} \mathrm{Si}_{0.05} \mathrm{~N}$, showing surface cracks and traces of buckling failure and lateral cracking: (b) Ti $i_{0.88} \mathrm{Si}_{0.12} \mathrm{~N}$ and $\mathrm{Ti}_{0.85} \mathrm{Si}_{0.15} \mathrm{~N}$, buckling failure with chipping and buckling failure with lateral cracking; (c) $\mathrm{Ti}_{0.70} \mathrm{Si}_{0.30} \mathrm{~N}$, showing conformal cracking and conformal cracking with lateral cracking and spallation.

has been identified. The buckling failure occurs as a result of the compressive stress field preceding the moving stylus and is characterised as a result of partial delamination (cohesive failure) of the coating at a certain distance ahead of the stylus. Once the stylus passes through, this partial lifting of the coating will be overridden and embedded into the bottom of the scratch track. These failures are illustrated in Fig. 2b. Finally, the films with the highest $\mathrm{Si}$ content $(x=0.30)$ present mainly conformal cracking for low loads. However, as the load increases, a large amount of lateral cracking starts to appear that becomes very frequent at the highest loads. Spallation within the lateral cracks in both sides of the scratch is also visible. These failures are illustrated in Fig. 2c. Conformal cracking occurs within the coating itself (cohesive failure) which is a characteristic of brittle coatings [3]. Spallation, which is the result of total delamination (adhesive failure), occurs only at the edges of the track, which might explain the appearance of the lateral cracking.

\subsubsection{Critical adhesion loads}

Fig. 3 shows the behaviour of both $\mathrm{L}_{\mathrm{C} 1}$ and $\mathrm{L}_{\mathrm{C} 2}$, as a function of Si content. Results were obtained by averaging the data for five different scratches in each sample.

The first observation that becomes clear from Fig. 3 is that the $\mathrm{Ti}_{1-x} \mathrm{Si}_{x} \mathrm{~N}$ system presents higher load values for total failure when compared with that of TiN, with the exception of the $\mathrm{Ti}_{0.70} \mathrm{Si}_{0.30} \mathrm{~N}$. In any case, this sample was produced without an adhesion layer, which is commonly accepted as being responsible for an increase in critical loads. For this system, higher critical loads were obtained for the $\mathrm{Ti}_{0.85} \mathrm{Si}_{0.15} \mathrm{~N}$, which presented an increase in both $L_{\mathrm{C} 1}$ (from 17 to 25) and $L_{\mathrm{C} 2}$ (from 70 to 76 ) values when the deposition temperature was raised from 300 to $400^{\circ} \mathrm{C}$. This seems to indicate that besides the adhesion layer, the deposition temperature is also a factor that may influence adhesion behaviour.

Regarding the Si content, the results are not yet conclusive to deduce the percentage that gives the best 


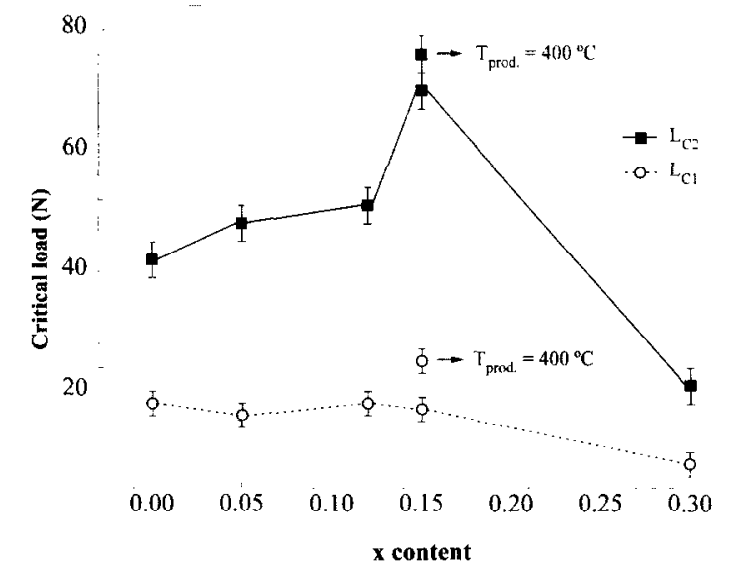

Fig. 3. Critical loads of $\mathrm{Ti}_{\mathfrak{r} x} \mathrm{Si}_{x} \mathrm{~N}$ samples as a function of $\mathrm{Si}$ content.

results, but the large difference in critical loads between $\mathrm{Ti}_{0.85} \mathrm{Si}_{0.15} \mathrm{~N}$ and $\mathrm{Ti}_{0.70} \mathrm{Si}_{0.30} \mathrm{~N}$ (even if we keep in mind that this second one has no adhesion layer), might indicate that 7.5 at.\% of $\mathrm{Si}$ is the composition that gives the best adhesion results. Another interesting factor is the possible correlation between the critical loads and the failure mechanism that prevails. In this respect, the $\mathrm{Ti}_{0.85} \mathrm{Si}_{0.15} \mathrm{~N}$ and $\mathrm{Ti}_{0.88} \mathrm{Si}_{0.12} \mathrm{~N}$ films, which revealed similar failure mechanisms, seem to indicate higher critical loads, whereas those with the lowest and highest $\mathrm{Si}$ contents, revealed lower critical loads.

A closer look at the X-ray diffraction patterns in Fig. 1 shows that the two coatings that reveal the best adhesion results show a strong (220) texture, whereas the others reveal a (200) texture for the highest $\mathrm{Si}$ content and a strong (111) texture for the lowest Si content. Regarding these observations, besides failure mechanisms, the microstructure is also an important factor contributing to the changes in critical loads.

\subsection{Hardness testing and Young modulus}

Conventional hardness values are obtained by measuring the diagonals $(d)$ of the remaining indentation after unloading. Among the different types of tests, the Vickers hardness testers, which use a four-sided pyramidal indenter, are widely used. One of the main problems associated with Vickers (and others) microhardness measurements is the apparent change in the hardness number with the change in indentation size. Possible explanations for this well-known phenomenon, the so-called indentation size effect (ISE), have been discussed extensively in the literature $[4,5]$. Recent developments in hardness testing by using ultra-low load hardness testers have enabled continuous monitoring of the load $(L)$ as a function of the depth of penetration (h) experienced by the indenter during the indentation process.

If a sequence of hardness measurements is made over a wide range of loads, it is clear that the results will be related to the hardness and thickness of the film as well as the substrate hardness. The criterion $h<0.1 t$ ( $t$ is the coating thickness) is well known and accepted as the condition that guarantees that the substrate influence is avoided, although some authors' claims that indentation depths of up to $25 \%$ of the film thickness, are accepted as revealing the hardness of the film, not yet influenced by the substrate are still worth of trust [6]. This requirement restricts the hardness tests with respect to depth and, in the case of very thin films that are gaining increasing interest, leads to some practical difficulties since the continuous decrease in depth could lead to values close to the roughness of the surface and affect the results considerably [7]. In our experiments, we use a method that enables the contribution of the substrate for the total measured hardness to be removed [8]. With this method, and for the maximum depth $\left(h_{\mathrm{i}}\right)$ at which the substrate is not yet influencing the value of the hardness [inflection point in the curve $\log$ (load) versus $\log h]$ and hence no plastic deformation of the substrate is observed, the hardness value of a film is obtained from:

$H_{\mathrm{f}}=H_{\mathrm{s}}+\left(h / h_{\mathrm{i}}\right) \cdot\left(H_{\mathrm{c}}-H_{\mathrm{s}}\right)$.

In addition to the corrections regarding the substrate influence, some geometrical calibration has to be taken into account due to the imperfections of the diamond indenter-the so-called indenter offset, which is specific for each piece of equipment and is usually responsible for higher values of hardness obtained, especially when the indentation depths are too low. For the equipment used in this work, the expression $h_{\text {corr. }}=0.052+1.095 h$ is used to correct the indention depth [9].

Young's modulus can be calculated from the slope of the initial portion of the unloading curve [10]:

$S^{-1}=\mathrm{d} h / \mathrm{d} P=\left(1 / 2 \cdot h_{\mathrm{Pc}}\right) \cdot(\pi / 24.5)^{1 / 2} \cdot\left(1 / E_{r}\right)$,

where $1 / E_{\mathrm{r}}=\left(1-v_{\mathrm{f}}^{2}\right) / E_{\mathrm{f}}+\left(1-v_{\mathrm{f}}^{2}\right) / E_{\mathrm{i}}$, with $E_{\mathrm{f}}$ and $v_{\mathrm{f}}$ being the young modulus and Poisson ratio for the film $\left(v_{\mathrm{f}}=0.25\right)$ and $E_{\mathrm{i}}$ and $v_{\mathrm{i}}$, the same quantities for the diamond indenter $\left(E_{\mathrm{i}}=1141 \mathrm{GPa}\right.$ and $\left.v_{\mathrm{i}}=0.07\right)$.

The variations in hardness and Young modulus as a function of the Si content are shown in Fig. 4. From this figure, two points deserve particular attention: first, an increase of approximately $70 \%$ in hardness is obtained by the introduction of $\mathrm{Si}$ in the TiN matrix. In any case, no significative differences were noted on the different $\mathrm{Ti}_{1-x} \mathrm{Si}_{x} \mathrm{~N}$ samples; second, a slight increase in hardness was observed when the substrate temperature was increased from 300 to $400{ }^{\circ} \mathrm{C}$.

\subsection{Oxidation behaviour}

All $\mathrm{Ti}_{1-x} \mathrm{Si}_{x} \mathrm{~N}$ samples were oxidised in a furnace and flushed with air for temperatures ranging from 500 to 


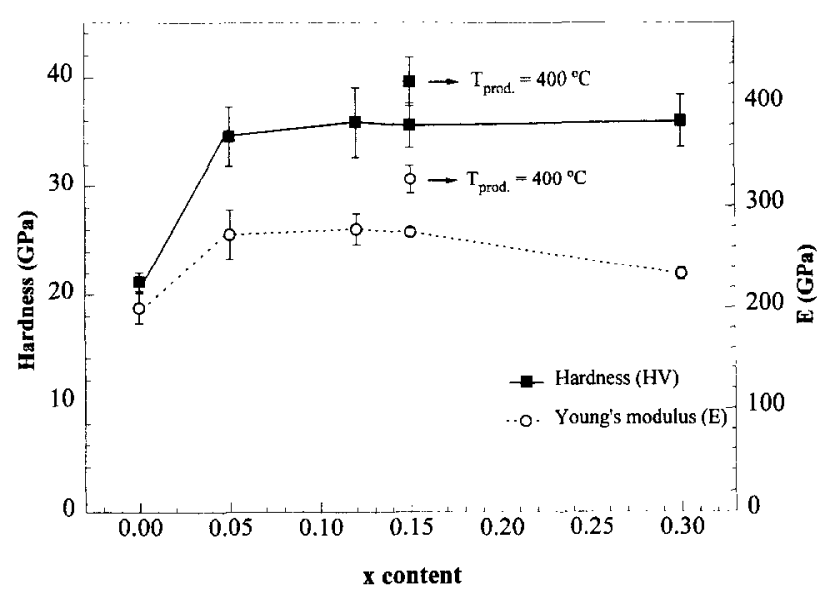

Fig. 4. Hardness and Youngs modulus of $\mathrm{Ti}_{1-x} \mathrm{Si}_{x} \mathrm{~N}$ samples as a function of $\mathrm{Si}$ content.

$850^{\circ} \mathrm{C}$. The atomic composition of the as-deposited samples and the depth profiles after annealing were measured via RBS.

The oxidation behaviour of these samples shows some significant differences with the Si content. For the lowest Si content, $\mathrm{Ti}_{0.95} \mathrm{Si}_{0.05} \mathrm{~N}$, the heat treatment at 700 and $800{ }^{\circ} \mathrm{C}$ over a period of $1 \mathrm{~h}$, revealed a total oxidation of the sample, which might be understandable since the composition is very close to that of stoichiometric TiN, which is known to undergo severe oxidation in this region of temperatures. For higher $\mathrm{Si}$ contents, the oxidation resistance becomes much higher, reaching its maximum for the $\mathrm{Ti}_{070} \mathrm{Si}_{030} \mathrm{~N}$ sample. Indeed, at $600{ }^{\circ} \mathrm{C}$. this sample already has an oxidation resistance that is about 100 times higher than that of TiN. Regarding the oxidation process itself, at the lowest temperatures, 500-600 ${ }^{\circ} \mathrm{C}$, the $\mathrm{Ti}_{1-x} \mathrm{Si}_{x} \mathrm{~N}$ system develops a homogeneous oxide layer composed of $\mathrm{Ti}, \mathrm{Si}$ and $\mathrm{O}$, with traces of $\mathrm{N}[11,12]$. For higher temperatures $\left(700-850^{\circ} \mathrm{C}\right)$ and for $0.12 \leq x \leq 0.30$, the oxide layer remains homogeneous, but the $\mathrm{N}$ content disappears. In any case, the oxidation resistance of these samples and in this region of temperatures is very similar to that of $(\mathrm{Ti}, \mathrm{Al}) \mathrm{N}$ $[11,12]$, which is known for its good performance in oxidising environments.

\section{Conclusions}

The results reported in this paper show a significative improvement in oxidation behaviour as well as in hardness values by the introduction of $\mathrm{Si}$ in the TiN matrix. Regarding the hardness measurements, the TiN hardness increased from about $22 \mathrm{GPa}$ to a value of about $36 \mathrm{GPa}$ with the introduction of $\mathrm{Si}$. Moreover, the deposition process also resulted in highly adhesive coatings to the substrate (IISS). In this respect, total failures for $\mathrm{Ti}_{0.85} \mathrm{Si}_{0.15} \mathrm{~N}$ during scratch tests were obtained for values as high as $70 \mathrm{~N}$, which represents an increase of more than $60 \%$ regarding those obtained for TiN. However, it should be noted that no significant changes were verified for the values corresponding to the appearance of the first failures $\left(L_{\mathrm{C} 1}\right)$. The $\mathrm{Ti}_{0.85} \mathrm{Si}_{0.15} \mathrm{~N}$, which showed the best adhesion behaviour, revealed buckling as the main failure mechanism and a strong (220) texture. However, the $\mathrm{Ti}_{0.70} \mathrm{Si}_{0.30} \mathrm{~N}$, which revealed the lowest critical loads, presents conformal cracking as the main failure mechanism and a (200) texture. For the sample with the lowest $\mathrm{Si}$ content, critical loads very close to those of TiN and a strong (111) texture were obtained. These findings indicate that the microstructure influences not only the oxidation resistance but also the adhesion behaviour. Another point that deserves a mention is the increase of about $10 \%$ for both $\mathrm{L}_{\mathrm{C} 1}$ critical load and hardness values obtained in the $\mathrm{Ti}_{0.85} \mathrm{Si}_{0.15} \mathrm{~N}$ sample when the substrate temperature was raised from $300^{\circ} \mathrm{C}$ to $400 \mathrm{C}$.

\section{Acknowledgement}

The authors gratefully acknowledge the financial support of the "Junta Nacional de Investigação Científica" (JNICT) during the course of this research under project no. PBICT/P/CTM/1962/95.

\section{References}

[1] V. Bellido-González, N. Stefanopoulos, F. Deguilhen, Surf. Coat. Technol. 7475 (1995) 884.

[2] P.J. Burnett, D.S. Rickerby, Thin Solid Films 154 (1987) 403.

[3] J.H. Je, E. Gyarmati, A. Naoumidis, Thin Solid Films 136 (1986) 57.

[4] M. Atkinson, J. Test. Eval. 19 (1991) 368.

[5] W. Mason. P.F. Johnson, J.R. Varner. J. Mater. Sci. 26 ( 1991 ) 6576.

[6] M.F. Doerner, D.S. Gardner, W.D. Nix, J. Mater. Res. 1 (1987) 845 . 
[7] C. Friedrich, G. Berg, E. Broszeit, C. Berger, Thin Solid Films 290291 (1996) 216

[8] J.V. Fernandes, A.C. Trindade, L.F. Menezes, Thin Solid Films, in press.

[9] A.C. Trindade, A. Cavaleiro, J.V. Fernandes, J. Test. Eval. 22 (1994) 365

[10] G.M. Pharr, W.C. Oliver, MRS Bull. 7 (1992) 28.
[11] F. Vaz, L. Rebouta, M.F. da Silva, J.C. Soares, in: Y. Pauleau, P. Barnas (Eds.), Protective Coatings and Thin Films: Synthesis, Characterization and Applications. Kluwer Academic, Dordrecht. 1996 , p. 501.

[12] F. Vaz. L. Rebouta. M.F. da Silva. J.C. Soares, Surf. Coat. Technol., in press. 